\title{
ПРОФИЛАКТИКА ПРОФЕССИОНАЛЬНЫХ ЗАБОЛЕВАНИЙ У МУЗЫКАНТОВ, ИГРАЮЩИХ НА ДУХОВЫХ ИНСТРУМЕНТАХ
}

\section{PREVENTION OF OCCUPATIONAL DISEASES IN MUSICIANS WHO PLAY WIND INSTRUMENTS}

\section{A. Ryazantsev \\ D. Arkhangelskaya}

Summary. Improving the playing of wind instruments requires a musician to have well-developed physical qualities, respiratory and cardiovascular systems. Often, many hours of lessons on a musical instrument lead to the emergence of occupational diseases. A scientifically based means of preventing windbreaks is swimming. In the swimming lessons at the conservatory, the method of breathing through a breathing tube has proven itself positively.

Keywords: playing wind instruments; functions of external respiration; occupational diseases; endurance; prevention of occupational diseases; swimming; breathing tubes.

\author{
Рязаниев Алексей Алексеевич \\ К.п.н., доцент, Астраханский государственный \\ медицинский университет \\ riazantsiev47@mail.ru \\ Архангельская Дарья Владимировна \\ Астраханский государственный медицинский \\ университет \\ knopka.m@list.ru
}

Аннотация. Совершенствование в игре на духовых инструментах требует от музыканта хорошо развитых физических качеств, дыхательной и сердечно-сосудистой систем. Нередко многочасовые занятия на музыкальном инструменте приводят к возникновению профессиональных заболеваний. Научно обоснованным средством профилактики духовиков является плавание. В учебных занятиях по плаванию в консерватории положительно зарекомендовал себя метод дыхания через дыхательную трубку.

Ключевые слова: игра на духовых инструментах; функции внешнего дыхания; профессиональные заболевания; выносливость; профилактика профессиональных заболеваний; плавание; дыхательные трубки. и з исторических источников известно, что музыка появилась на свет одновременно с сотворением мира [10]. Древние философы: Пифагор, Платон, Аристотель отмечали благотворные влияния музыки на человека. И наши современники согласны с тем, что виртуозное музыкальное исполнительство влияет на эмоциональное состояние и настроение, преобразует душу, помогает в работе, стимулирует мозговую деятельность. Но виртуозность музыканта, его исполнительское мастерство достигается кропотливыми, многочасовыми занятиями с раннего возраста. И нередко за это увлечение музыкой приходится расплачиваться своим здоровьем. Статистика неумолима: около $90 \%$ музыкантов во всем мире страдают профессиональными заболеваниями, и в $72 \%$ случаев эти заболевания диагностируются у лиц моложе 25 лет, то есть во время учебы в консерватории [10]. От профессиональных заболеваний страдали Р. Шуман, С. Рахманинов, Д. Шостакович, Г. Нейгауз, Я. Флиер. Актуальность проблемы сохраняется и в наши дни. Профилактикой и лечением профессиональных заболеваний занимаются Институт здоровья музыкантов имени Курта Зингера в Берлине и научно-исследовательский институт имени Петера Оствальда при Кёльнской консерватории [10]. В России исследованием и профилактикой профессиональных заболеваний музыкантов занимаются в пензенском институте усовершенствования врачей и в Благотворительном фонде Владимира Спивакова.

Особенно актуальны вопросы, связанные с профилактикой профессиональных заболеваний музыкантов, совершенствующихся в игре на духовых инструментах. К физическим качествам и функциям именно этой категории музыкантов предъявляются особенно большие требования, именно они находятся в зоне особого риска. К наиболее частым профессиональным заболеваниям музыкантов-духовиков относятся эмфизема легких, варикозное расширение вен нижних конечностей и другие, не менее серьезные недуги, к полной или частичной потере трудоспособности [5]. Не случайно, депутат Государственной Думы РФ совместно с Министерством культуры РФ предпринимают усилия для того, чтобы приравнять исполнителей на духовных инструментах к артистам цирка, что даёт право выхода на пенсию после 25 лет творческого стажа [5]. Член международной гильдии трубачей Сергей Пронь констатирует: «...проводились исследования, согласно которым час игры на трубе приравнивался по количеству 
физических затрат к рабочему дню человека, разгружающего уголь [5]».

Анализ научно-исследовательской и методической литературы, результаты педагогических наблюдений и анкетирование специалистов показали, что в исполнительской деятельности музыкантов, играющих на духовных инструментах, особенно важное профессиональное значение придаётся функции внешнего дыхания (исполнительский вдох и исполнительный выдох [1].

Игра на духовых инструментах требует от исполнителей определённой специфичности его дыхания [1]:

- при обычном нормальном дыхании обе фазы дыхания (вдох и выдох) по времени примерно равны, а при игре на духовых инструментах вдох делается коротким, а выдох - продолжительным;

- в процессе игры на духовом инструменте обе фазы дыхания совершаются вынужденно-произвольно и зависят от построения данных музыкальных фраз;

- исполнитель на духовом инструменте вынужден доводить дыхательные изменения в легких до максимальных значений, то есть использовать всю «жизненную ёмкость легких» (ЖЕЛ);

- при игре на духовных инструментах выдох музыканта вынужден происходить под значительным давлением, так как выдыхаемому воздуху необходимо выходить из легких продолжительной и легкой струёй и одновременно преодолевать на своей пути препятствия: узкую губную щель, узкое отверстие мундштука и др. При этом наблюдается значительная нагрузка на выдыхательные мышцы, происходящая при одновременной активизированной деятельности и их антагонистов-вдыхателей, особенно важнейшей выдыхательной мышцы - диафрагмы;

- при обычном нормальном дыхании человек дышит преимущественно через нос. В момент игры дыхание осуществляется при активном участии рта.

Специфичность исполнительского дыхания при игре на духовых инструментах связана с отклонением от обычных физиологических норм, что не может пройти бесследно для организма музыкантов. Частая искусственная задержка дыхания способствует частичному нарушению газообмена в лёгких, что обуславливает недостаточно полный приток кислорода в организм [1]. Необходимость выдыхать воздух почти непрерывной струёй под большим давлением требует от музыканта значительных и интенсивных нагрузок, которую испытывают при игре легкие и сердце играющего. Профессионально важным физическим качеством для играю- щего на духовом инструменте является выносливость [9].

Ухудшение газообмена и увеличение резервного объема выдоха говорит о скрытой эмфиземе легких у музыкантов, играющих на духовных инструментах [8]. А длительное и частое повышение внутрибрюшного давления, обусловленное напряжением брюшной стенки, создает препятствие к оттоку крови из вен нижних конечностей, что предрасполагает к варикозному расширению вен. Игра, в положении стоя, при которой отсутствует сокращение мышц нижних конечностей и отток крови из глубоких и поверхностях вен ног, усугубляют этот процесс.

Исполнители на духовых инструментах отмечают необходимость и большую значимость физических упражнений и видов спорта, как в процессе совершенствования исполнительской техники, так и в области профилактики и терапии профессиональных заболеваний [6;8]. Целый ряд специальных упражнений для укрепления функций внешнего дыхания предложены педагогами-музыкантами [8].

Научно обоснованным и профессионально важным видом спорта для музыкантов-духовиков является плавание [1]. Продолжительность вдоха над водой при быстром плавании достигает 9 метров/сек., то есть максимальной величины, регистрируемой в обычных условиях на пневмотахометре. При быстром плавании дыхательные мышцы сокращаются с максимальной силой и быстротой, что профессионально важно для исполнительской деятельности музыканта-духовика [8]. Все эти факторы характеризуют плавание как одно из эффективных средств у занимающихся и достижения ими высокого уровня показателей ЖЕЛ, максимальной вентиляции легких (МВЛ), пневмотахометрии [8]. Улучшаются аэробные и анаэробные возможности организма, что способствует совершенствованию физического качества выносливости.

Пребывание в воде является эффективным средством закаливания, так как вода, по сравнению с воздухом, в 28 раз сильнее поглощает тепло с кожных покровов тела. Терморегуляция организма в воде - важное средство в профилактике простудных заболеваний, составляющих до 40\% общей заболеваемости студентов. Холодовой раздражитель в виде воды воздействует на улучшение умственной работоспособности даже более эффективно, чем физическим упражнения [3].

С точки зрения формирования исполнительского дыхания музыканта занятие плаванием заслуживает внимание тем, что дыхание при плавании затруднено следующим образом [3]: 
- в отличие от обычного условия, где фаза выдоха пассивна, при плавании выдох в воду становится активным;

- выполнение вдоха затруднено давлением на грудную клетки, составляющем 12,5-15г/см2.

Плавание также является средством профилактики и методом лечения различных заболеваний, в том числе и профессиональных [3]. Исследования М. Навратила с соавторами показал, что плавание является эффективным средством профилактики эмфизематозных заболеваний легких у музыкантов-духовиков, так как при погружении тела в воду повышается окружающее давление, легочные объемы уменьшаются, и остаточный объём воздуха в легких уменьшается в воде примерно на 100-200 мм [4].

При плавании горизонтальное положение тела значительно облегчает работу сердца, так как в этих условиях отсутствует сила тяжести, являющаяся препятствием для продвижения крови от вен нижних конечностей, что является профилактикой варикозного расширения вен [4].

Плавание играет существенную роль в профессиональной деятельности исполнителей на духовных инструментах, так как оказывает положительное влияние на респираторную систему музыканта и совершенствует ее функцию [8].

В педагогическом эксперименте, проводимым в Астраханской государственной консерватории проверялась эффективность внедрения плавания в учебной процесс по физическому воспитанию для студентов, совершенствующихся в игре на духовных инструментах. Методология исследования включала в себя теоретический анализ литературных источников, анкетирование, педагогические наблюдения и врачебный контроль, спирографию, пнемотахометрию, пробы Штанге и Тенга, определение физической работоспособности (PWC170), математическую статистику. Общее количество часов, запланированных на физическое воспитание, в том числе и на плавание, не выходило за рамки программных требований.

Эксперимент показал, что внедрение плавания в учебный процесс достоверно улучшило изменение функционального состояние кардиореспираторной системы студентов-духовиков, их физическую подготовленность (особенно в кроссовых дисциплинах) и состояние здоровья. Значительно сократилось количество занятий, пропущенных по медицинским показателям, особенно простудного характера, негативно влияющим на функцию исполнительского дыхания [7]. Проведение занятий по физическому воспитанию с профессиональной направленностью оказало положительное влияние на динамику оценок по музыкальной специальности и общей успеваемости студентов.

Для эффективного улучшения учебно-тренировочного процесса и эмоциональной окраски занятий нами применяется метод дополнительного «мертвого пространства» (ДМП) [7]. Этот метод путём изменения количественных соотношений газового состава вдыхаемого воздуха способствует увеличение выносливости и улучшению работоспособности организма студентов, повышает вентиляцию легких, максимальное потребление кислорода, увеличивает ЖЕЛ, мощность форсированного вдоха, глубину дыхания. Именно те физические качества и функции, которые имеют профессионально большое значение в исполнительской деятельности музыкантов-духовиков [2,7]. Метод «ДМП» также оказывает положительное воздействие на кровеносную систему и состав крови (увеличивается содержание эритроцитов, лейкоцитов, гемоглобина, повышается концентрация молочной кислоты, снижается резервная щёлочность) и улучшает выделительные функции $[2,7]$.

Суть метода в том, что пловец выдыхает воздух в трубку и затем вдыхает этот воздух из трубки. Таким образом, газообмен с окружающим пространством замедляется. С окружающим пространством воздух, находящийся в трубке, смешивается лишь частично, поэтому в нем пониженное содержание О2 и повышение CO2. Относительная гипоксия и гиперкапния вызывает возбуждение дыхательного центра, и увеличение вентиляции легких происходит, главным образом, за счет увеличения глубины дыхания.

При проведении учебных занятий по плаванию «методом ДМП» нами применялись дыхательные трубки от комплекта аквалангиста (трубка, ласты, маска). В качестве носового нами использовались зажимы от оксиспирографа «мета 1-25», хотя использование любых зажимов для этой цели не представляет трудности.

В настоящее время налажено производство дыхательных трубок для плавания «сноркель», в которых существуют специальные насадки с разными отверстиями для уменьшения диаметра трубки и поступления кислорода в легкие пловца. Это даёт возможность отработки специальных упражнений и тренировки дыхательной мускулатуры [2].

Дыхательную трубку «сноркель» можно использовать для занимающихся любого возраста и уровня подготовки, но менее опытным пловцам рекомендуется надевать ласты [2]. 


\section{ЛИТЕРАТУРА}

1. Белизов Г.А., Марков Д.С. К вопросу о профессионально-прикладной физической подготовке учащихся музыкальных училищ //матер. IV Всесоюзн. науч.-метод. конф. по профессионально-прикладной физической подготовке (Клайпеда, 1975). — М., 1975. — c. 17-19.

2. Для чего пловцам нужно плавать с трубкой. Режим доступа: https://www.swimrocket.ru/blog/dlya-chego-plovtsam-nuzhno-plavat-s-trubkoj/ (Дата 0бращения 23.02.2021).

3. Куренков Т.И. Внешнее дыхание и газообмен при плавании [Текст]: Авторефреферат дис. на соискание ученой степени канд.биолог.наук. / Центр. науч.-исслед. ин-т курортологии и физиотерапии.—- Москва: [б. и.], 1968.— 22 с.

4. Навратил М., Кадлец К., Даум С. Патофизиология дыхания [Текст]: М., «Медицина», 1967, с. 43.

5. Оганджанов И. Вокалистов и духовиков приравняют к артистам цирка за вредность профессии. Режим доступа: https://russian.rt.com/article/323685vokalistov-i-du. (Дата обращения 23.02.2021).

6. Остапкович В.Е., Брофман А.В. Профессиональные заболевания ЛОР-органов / В.Е. Остапкович, А.В. Брофман — М.: Медицина, $1982 .-100$ с.

7. Рязанцев А.А. Применение метода дыхания через дополнительное «мертвое» пространство в условиях учебного процесса. XXII Международная научно-практическая конференция по проблемам физического воспитания учащихся «Человек, здоровье, физическая культура и спорт в изменяющемся мире»: (матер. конф.) (5-7 окт. 2012 г.).— Коломна, 2012.— - 82-84.

8. Шнайдер А.А. Функциональное состояние кардиореспираторной системы и физическая работоспособность музыкантов различных специальностей [Текст]: Автореф.дис.канд.биолог.наук.—Фрунзе, 1988. - 18 с.

9. Gibson T.M. «The respiratory stress of playing the bagpipes». J/ Physioe (Great Britan), 1971.— 291, p. $24-25$.

10. Occupational diseases of musicians, dancers and artists. Режим трубка: https://osteomed.su/professionalnye-zabolevaniya/ (Дата 0бращения 23.02.2021).

( Р Рязанцев Алексей Алексеевич ( riazantsiev47@mail.ru ),Архангельская Дарья Владимировна ( knopka.m@list.ru ).

Журнал «Современная наука: актуальные проблемы теории и практики»

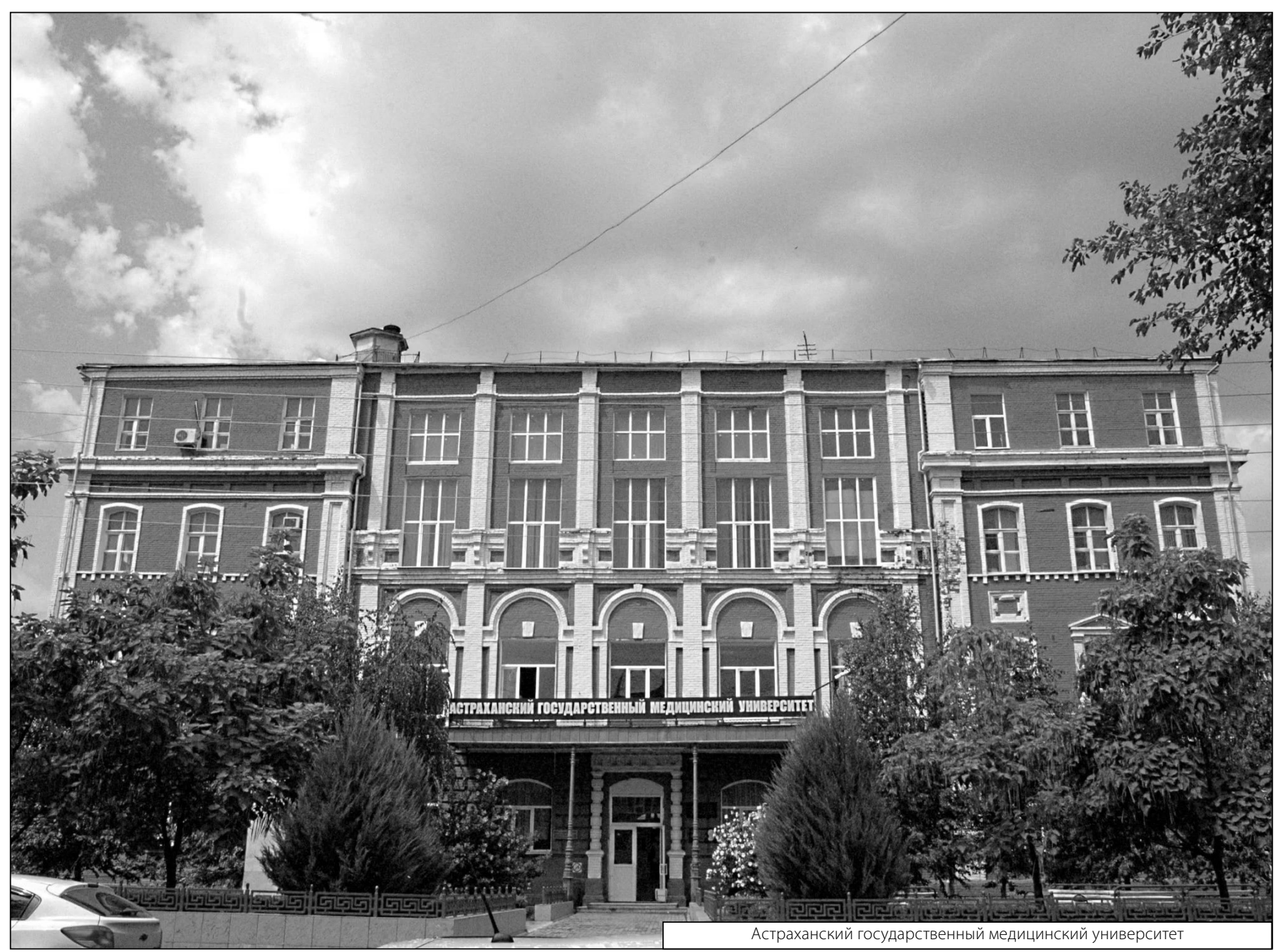

